\title{
MILLEKS MULLE EESTI KEEL? RIIGIKEELE OSKUSE VAJALIKKUSEST VENE KOOLINOORTE PILGU LÄBI
}

\author{
Birute Klaas-Lang, Kristiina Praakli
}

\begin{abstract}
Ülevaade. Artikli eesmärk on analüüsida vene õppekeelega üldhariduskoolide 9. klasside õpilaste hoiakuid riigikeele oskuse vajalikkuse suhtes. Õpilastega läbi viidud poolstruktureeritud rühmaintervjuud toovad riigikeele õppe senistesse diskussioonidesse keeleõppija, st 15-16-aastase vene koolinoore hääle. Ainestiku diskursiivne analüüs näitab, et koolinoorte hoiakutes riigikeele õppimise ja oskuse suhtes tõusevad esile arusaamad eesti keele väiksusest, piiratud kasutusvõimalused lähikeskkonnas, eri keelte roll tööturul, aga ka õpilaste rahvuslik ja keeleline enesemääratlemine. Ühe põhitulemusena võib välja tuua, et 9. klassi koolinoore silmis on eesti keelel peamiselt vaid instrumentaalne väärtus, st keelt nähakse vahendina eneseteostuse saavutamisel. Vene koolinoor ei näe eesti keelt oma identiteedi ühe komponendina ning seab võrdluses maailma suurkeeltega eesti keele jätkusuutlikkuse (ning seeläbi eesti keele õppimise otstarbekuse) kahtluse alla.*
\end{abstract}

Võtmesõnad: motivatsioon, hoiakud, vene kool, eesti keel

\section{Sissejuhatus}

\subsection{Rahvusvaheline taust ja teoreetiline raamistik}

Käesolevas artiklis on vaatluse all põhikooli kolmanda kooliastme 9. klasside õpilaste argumentatsioon riigikeele õppe teemadel (st kuidas kõneldakse riigikeelest, selle õppimisest, kasutamisest ning tulevikuväljavaadetest) poolstruktureeritud rühmaintervjuudes. Kuigi eesti keele õpe on esmajoones Eesti kui rahvusriigi küsimus, ei saa eesti keele õpet ning sellega seotud hoiakuid vaadata lahus globaalsest keelekeskkonnast, tõstatades ka mikrotasandil küsimuse eri keelte vajalikkusest,

* Artikkel põhineb uuringul "Arvamusi ja hinnanguid riigikeele õppe korraldamise kohta vene õppekeelega koolides" (Klaas-Lang jt 2014), mille eesmärk oli avada riigikeele õppimise tulemuslikkuse lahknevuse tagamaid. Uuringuga kontrollis töörühm muuhulgas ka hüpoteesi, kas riigikeele eksamitulemuste ligi kahekordne erinevus n-ö edukate ning vähem edukate koolide lõikes põhikooli lõpus võib kooli asukoha (eesti- vs. venekeelne keskkond) ning sotsiaal-majanduslike tegurite kõrval johtuda ka riigikeele õppe suhtes valitsevate hoiakute erinevusest. Artikli autorite kõrval osalesid uuringu läbiviimisel veel Alla Lašmanova ning Anni Peedisson. 
nende rollidest ning tulevikuväljavaadetest. Keeleline mitmekesistumine, keelte võimusuhete ja prestiiži muutumine ning ümberhindamine, migratsioon ja turism, infotehnoloogia ning sotsiaalmeedia esiletõus on oluliselt mõjutanud ka Eesti keelekeskkondi ning nende kõnelejate hoiakuid eri keelte suhtes. Tulenevalt ühe või teise keele geopoliitilisest positsioonist ja arengust, kujunevad ühed keeled olulisemaks kui teised. Tingimustes, kus keelte varasemad rollid ja paiknemine rahvusvahelistel suhtlusväljadel on ümber mängitud (vrd inglise, hiina, hindi, araabia vs. saksa ja prantsuse keel), jäävad paljud väikekeeled senisest haavatavamasse positsiooni. Eeskätt satub ohtu nende atraktiivsus konkurentsisuutlike sihtkeeltena võõrkeeleõppes, isegi kui keel on riigikeel. Uue võõrkeele õppimine ei tähenda ainult keele struktuuri ja sõnavara omandamist, vaid tagab ka juurdepääsu ülemaailmsetesse selle keele võrgustikesse. Võrdluses maailma suurkeeltega on eestikeelsed võrgustikud oluliselt piiratumad nii globaalses, lokaalses kui ka individuaalses võtmes. Niisugustes muutunud keeleoludes on võõrkeeleõpe, õppimise motivatsioon ja strateegiad ning õppijate-kõnelejate hoiakud ühe või teise keele suhtes üha enam uurijate huviorbiidis. Eelpool toodu valguses tõusebki senisest rohkem esile küsimus keeleõppe motivatsioonist ning hoiakutest, mida käesolevas artiklis püütakse avada 15-16-aastase vene koolinoore silme läbi.

Keeleõppeprotsessi mõjutavate tegurite hulk on tohutu: need hõlmavad individuaalseid, sotsiaal-majanduslikke, kultuurilisi, kognitiivseid, psühholoogilisi ning mitte-keelelisi faktoreid (detailne ülevaade Jalkanen, Ruuska 2007: 27-44). Nimetatuist olulisimad on tundetegurid ehk motivatsioon, hoiakud, õppija keeleline minapilt ning keelehirm, mis mõjutavad kõige otsesemalt seda, milliseks kujuneb õpilase suhe õpitavasse keelde ja õppeprotsessi ning valmisolekusse keelt suhtluses kasutada (Jalkanen, Ruuska 2007: 27, vt ka Pihko 2007). Viimast rõhutab ka "Euroopa keeleõppe raamdokument" (EKR 2007: 110): "Keelekasutaja või -õppija suhtlustoimingut ei mõjuta mitte ainult tema teadmised, arusaamad ja oskused, vaid ka tema eneseteadvusega seotud tegurid - hoiakud, motiivid, väärtushinnangud, veendumused, kognitiivsed stiilid ja isiksustüüp...”.

Motivatsioon ning hoiakud ongi võõrkeele omandamist mõjutavad põhitegurid. Mõistetena on mõlemad üksjagu problemaatilised ning nende defineerimine pole alati selge (vt Klaas 1992, Dörnyei 1998: 117-122, Gardner 2010: 1-29). Võõrkeele õppimise, õpetamise ning keeleõppe motivatsiooni süstemaatiline uurimine algas 1970. aastatel ning sellealase kirjanduse hulk on väga suur (vt nt Dörnyei 1998, 2001, Dörnyei, Schmidt 2001, Dörnyei 1998, 2001a, 2001b, Mitchell, Myles 2004, Ellis, Barkhuizen 2005, Ellis 2008). Valdkonnale aluse pannud Kanada teadlase Robert Gardneri (1985) keeleomandamise sotsiaalhariduslik mudel (ingl socioeducational model) on endiselt enim rakendatav teoreetiline raamistik, kuigi seda on ka rohkesti kritiseeritud. Gardner $(1985,2010)$ eristab integratiivset ja instrumentaalset motivatsiooni. Integratiivne motivatsioon tähendab õppija positiivset huvi sihtkeele kõnelejate ja kultuuri vastu, keelt õpitakse keelelise ja kultuurilise lõimumise soovist. Keeleõppe eelduseks on õppija positiivne hoiak ning soov olla interaktsioonis selle keele kõnelejaskonnaga. Seevastu instrumentaalne motivatsioon on seotud keeleõppe praktiliste eesmärkidega, mille taustal on uue keele oskusest saadav praktiline kasu ja soodustused. Keele oskamine on seega vahend, mille kaudu võib keeleõppija püüda saavutada majanduslikku kasu või paremat sotsiaalmajanduslikku positsiooni. 
Gardneri oponendid näevad mudelit piiratud raamistikuna, mis jätab kõrvale muud keeleõpet mõjutavad tegurid (nt Dörnyei 2003: 4-23), samuti on kriitikat pälvinud instrumentaalse-integratiivse motivatsiooni suhe ning on esitatud kaalukaid vastuargumente integratiivse motivatsiooni kui keeleõppeprotsessi ainuliselt tulemuslikult suunava motivatsiooni suhtes. Mitmed uurimustulemused on näidanud (vt nt Knight 2013: 18-23), et võõrkeele õpimotivatsiooni taustal on oluliselt rohkem tegureid, muuhulgas füüsiline ja sotsiaalne keskkond, kus õpe aset leiab, õppematerjalid, õpetaja isik jne. Keeleõppekeskkonnas, kus õppijate kontaktid seda keelt emakeelena kõnelejatega on piiratud või puuduvad sootuks - Eesti näitel mitmed keelekeskkonnad Ida-Virumaal - võibki integratiivne motivatsioon jääda tagaplaanile, kuna keeleõppijal puudub tema keelelist arengut toetav "keelesild" emakeelekõnelejatega, kuid keeleõppeprotsess võib sellele vaatamata edukas olla. Artikli tulemustest ette rutates võib väite kinnituseks tuua näiteks üldhariduskooli Ida-Virumaal, mille õpilastel puuduvad kooliväliselt igasugused kontaktid eesti keele kõnelejatega, ometi on see kool riigieksami tulemuste poolest esirinnas. Seega ei pruugi integratiivse motivatsiooni puudumine olla keeleõpet pärssiv tegur.

Niisama oluline mõiste on ka demotivatsioon (lähemalt Dörnyei 2001a: 50-51, 2001b: 141-155) ehk õppimist takistavad tegurid, nagu näiteks oskamatu õpetaja, viletsad kooliruumid, igav õpik ja halvasti koostatud õppematerjalid, aga ka negatiivne hoiak õpitava keele ja selle kõnelejate suhtes, õppeaine kohustuslikkus jne. Keeleõppe kohustuslikkuse avalikud diskussioonid on ilmselt tuntuimad Soome riigi keelevaidluste näitel, kus teise riigikeele ehk rootsi keele, Soomes tuntud kui pakkoruotsi, kohustuslik ôppimine on Soome avalikkuses olnud intensiivseks aruteluküsimuseks viimastel aastakümnetel. ${ }^{1}$ Käesoleva artikli autoritele teadaolevalt pole demotivatsioonitegureid vene koolide kontekstis Eestis uuritud, küll aga võib intervjuuainestikule tuginevalt välja tuua õpilaste kriitika kasutatavate õppematerjalide, grammatikakeskse õpetamise ning ootuspäraselt ka aine kohustuslikkuse ning riigikeele pealesunnitud õppe kohta, kui nimetada mõningaid keeleõppimist pärssivaid tegureid (vt lähemalt Klaas-Lang jt 2014).

Seega pole keeleõppes vähem olulised ühiskonnas või vahetus õpikeskkonnas valitsevad hoiakud ning arusaamad keeleõppe tähtsuse ja vajalikkuse kohta ning meedia roll arvamuse kujundajana, kinnistajana ning taastootjana, mis ulatuvad järellainetena ka kooliruumi ning keeletundi. Teine oluline mõiste, mida artiklis käsitletakse, ongi hoiak (ingl attitude). Ingliskeelses kirjanduses on hoiakut defineeritud näiteks kui tunnet mingi psühholoogilise objekti poolt või vastu, rõhutades sellega positiivseid ja negatiivseid emotsionaalseid vastuseid, mida hoiak väljendab (vt Garrett 2010: 19 ja sealsed viited). "Euroopa keeleõppe raamdokument" mõistab hoiakut keelekasutaja või -õppija avatusena uutele kogemustele, teistele inimestele, ideedele, rahvastele, ühiskondadele ja kultuuridele ning huvile nende vastu, valmisolekut suhestada oma kultuurilised seisukohad ja väärtushinnangute süsteem ning olla valmis ja suuteline kaugenema juurdunud hoiakutest ja saada aru kultuurierinevustest (EKR 2007: 123-124). Kui motivatsioonist rääkides rõhutatakse selle dünaamilisust ja situatsioonikesksust, siis hoiakute puhul on küsimus püsivamast ilmingust, mis võib küll aja jooksul muutuda.

Teemast lähemalt: Kaksi kantaa pakkoruotsista. http://www.hs.fi/sunnuntai/a1305708043006 (10.10.2014). 


\subsection{Eesti vene õppekeelega koole käsitlev diskursus}

Viimased viisteist aastat on Eesti vene õppekeelega koolide olukord leidnud mitmekülgset kajastamist nii laiale avalikkusele suunatud meediaartiklites kui ka rohketes uurimustes, mis analüüsivad riigikeele õpet, selle teoreetilist ja keelepoliitilist alust, realiseerumist praktikas, samuti suhtumisi ja hoiakuid ning muid keeleõpet mõjutavaid tegureid. Tähelepanu keskmesse on tõusnud vene kool pärast üleminekut osalisele eestikeelsele aineõppele gümnaasiumiastmes, mille tulemuslikkus on viimasel paaril aastal leidnud käsitlemist mitmetes raportites (nt Klaas-Lang jt 2014, Metslang jt 2013).

Vene õppekeelega koolide olukorda ja riigikeele õpet on käsitletud mitmetes uurimustes (vt ülevaated Vaiss 2009, Klaas-Lang jt 2014). Eraldi tasub nimetada eesti keele seisundit ja õpetamise olukorda analüüsivat ülevaadet (Vare 2004), TNS Emori uuringuid eestikeelse aineõppe hetkeolukorrast ja vajadustest ning mitte-eestlaste teadlikkusest ja suhtumisest vene õppekeelega koolide üleminekusse eestikeelsele aineõppele (TNS Emor 2006, TNS Emor 2008), Tallinna Ülikooli uurijate koostatud venekeelse kooli kakskeelse õppe uuringut (Metslang jt 2013), eestivenelaste keeleoskuse ja gümnaasiumireformi suhtumiste uuringut (Proos 2005), eestivene noorte positsiooni ja ootuste kajastust (Proos, Pettai 2008).

Keelehoiakute uurimisest eesti keeleteaduses väärib esiletõstmist Kadri Koreiniku doktoritöö (2011) ning artiklid, milles autor analüüsib keeleideoloogiaid ning keelelisi representatsioone lõunaeesti keele avalikus diskursuses. Koreiniku ja Praakli ühisartiklis (2013) oli vaatluse all keele kestlikkuse ja kao diskursiivne konstrueerimine Saksamaa ja Soome eestlaste ning setu ja võru keele kasutajate poolstruktureeritud intervjuude näitel. Martin Ehala ning Anni Tammemägi (2012) on uurinud eesti koolinoorte hoiakuid inglise keele kasutamise suhtes, valmisolekut muulaste keeleliseks integratsiooniks ning eesti keele kasutamist segaperekonnas. Natalia Vaiss (2009) on vaadelnud vene õppekeelega põhikooli õpilaste ja õpetajate hoiakuid eestikeelse aineõppe suhtes enne gümnaasiumireformi.

\section{Uuringu meetod, informandid ja ainestik}

Motivatsiooni ning hoiakute uuringutes rakendatakse ainestiku kogumisel nii kvantitatiivseid kui ka kvalitatiivseid meetodeid, põhiliselt kas küsimustikke või intervjuusid (vt nt Vaiss 2009, Ehala, Tammemägi 2012, Koreinik, Praakli 2013). Käesoleva artikli ainestik on kogutud otsese meetodiga (ingl direct approach, vt lähemalt Garrett 2010: 37-38), milleks on poolstruktureeritud rühmaintervjuud. Üks tavalisemaid intervjuude analüüsimise meetodeid on intervjuudes osalenute öeldu taandamine sisukategooriateks ning informatsiooni koondamine erinevate teemade alla (lähemalt Koreinik, Praakli 2013: 135). Artikli analüüsiosas lähtumegi sellest, mida ühe või teise teemaga seoses intervjuudes räägiti, eesmärgiga näidata, millisena näeb vene koolinoor eesti keele oskust ja vajalikkust.

Uuringu informandid on 15-16-aastased koolinoored, kes õpivad vene õppekeelega põhikoolis, st koolis, kus suurem osa õppetööst toimub vene keeles. Õpilased olid valitud õppeasutuse 2013. a riigieksami tulemuste järgi kaheksast põhikoolist (neli edukamat ja neli vähem edukamat kooli), mis paiknesid Tallinnas, Tartus 
ning Ida-Virumaal. Uuringus osalenud õppeasutused tegutsevad geograafilise asukoha ning keskkonna rahvusliku struktuuri võrdluses üksteisest vägagi erinevas keelekeskkonnas. Uuringu tulemustest rääkides toome eraldi välja edukate ning vähem edukate koolide õpilaste seisukohad. Kokkuleppel õppeasutustega säilitame artiklis koolide ning õpilaste anonüümsuse ning õppeasutuse nimesid ei maini. Eesti keele teise keelena lõpueksami tulemuste detailse statistika koolide lõikes leiab sihtasutuse Innove veebilehelt. ${ }^{2}$ Artikli autorid rõhutavad, et artikli eesmärk on tuua kuuldavale vene noore hääl, mitte koole omavahel võrrelda.

Uuringuks vajalik ainestik koguti poolstruktureeritud rühmaintervjuude vormis, järgides kvalitatiivse uuringu tavapäraseid protseduure. Intervjuude pikkus oli 90 minutit ning nendes keskenduti neljale põhiteemale:

1) riigikeele kasutus õpilaste argielus;

2) õpilaste hinnang oma riigikeele oskuse kohta;

3) riigikeele õppimise olulisus;

4) õpetaja, kooli ja riigi roll riigikeele õppes.

Intervjuud viidi läbi vene keeles ning need toimusid klassiruumis. Kuigi kõik intervjuud lähtusid samadest põhimõtetest, ei saa välistada mõningast vestlusteemade varieeruvust. Nii nähtub intervjuuainestikku koolide kaupa kõrvutades, et eeskätt vähem edukate koolide õpilased toovad omaalgatuslikult sisse eesti ja vene noortevahelised suhted, keelekeskkonna olulisuse keeleõppes ning eesti keele tulevikuväljavaated. Samuti peatusid nad teiste koolide eakaaslastest rohkem perede sotsiaal-majanduslikul olukorral ning erinevatel võimalustel koolivälise keeleõppe toetamiseks. Kuigi õpilaste sotsiaal-majanduslik taust ei kuulunud otseselt intervjuude teemade hulka, näitab küsimuse esiletõus probleemi seost keeleõppe edukusega. Kõneka vestlusteemana tõuseb esile eesti keele tuleviku ning Eestist emigreerumise argumentatsioon. Kuna empiiriline ainestik on kogutud rühmaintervjuude vormis, tuleb arvesse võtta võimalikku rühmadünaamikat küsimustele vastamisel (klassikaaslastevahelised suhted, mõne õpilase domineerimine või tagaplaanile jäämine jne).

\section{Tulemused}

\subsection{Riigikeele oskus ja kasutus õpilaste igapäevaelus}

Informantidele esitati kolmeosaline põhiküsimus "Kellega, kui tihti ja kus räägite eesti keelt?" eesmärgiga hinnata eesti keele kasutamise sagedust õpilaste argisuhtluses ning selgitada välja eesti keele kasutusväljad. Kuna küsimuse eesmärk oli saada üldpilt koolinoorte keelekeskkonna olemusest, piirduti selle määratlemiseks rühmaintervjuuga. Detailsem analüüs, mis võtaks arvesse keelekasutusväljade võimalikult laia spektrit (nt keelevalikud kodus ja suhtlusvõrgustikes ning avalikus ruumis), vajab ankeetküsitluse vormi ning kvantitatiivseid meetodeid. Põhikoolis õppiva vene koolinoore eesti keele kasutusvõimalustest võib üldistada tüüpilised keelekasutusväljad, kus riigikeele kasutamine piirdub üldjuhul õpilase eesti keele tundidega, vahel ka ainetundidega (v.a Tartu ja Tallinna koolinoorte puhul).

2 http://www.innove.ee (10.10.2014). 
(1) Eesti keeles räägime eesti keele tunnis.

(2) Mõnikord saab poes kasutada, aga mitte Narvas.

Eesti keele kasutamise võimalused väljaspool koolikeskkonda johtuvad suuresti haridusasutuse geograafilisest asukohast. Sestap on ootuspärane, et kõige rohkem võimalusi eesti keele kasutamiseks on Tartu õpilastel, kelle tüüpvastuseks eesti keele kasutuse kohta väljaspool klassi- ja kooliruumi oli kasutame igal pool. Ka Tallinna kooliõpilastel on oluliselt rohkem eestikeelseid kontakte kui näiteks Narva õpilastel. Eesti keelt kasutatakse Tallinnas ja Tartus ka huviringide keelena (Käin võrkpallitrennis, seal saan keelega hästi hakkama; Käin tantsuringis ja seal suhtlen. Trennis suhtleme palju). Samas on ka Tallinnas oluliseks mõjuriks kooli geograafiline asukoht ning õpilase elukoht, mis tingib ja kujundab õpilase suhtlusvõrgustike struktuuri (Meie linnaosas on ikka eestlasi rohkem, eesti keelt on igal pool kuulda). Võiks eeldada, et eestikeelne meedia, mis on ju kättesaadav elukohast sõltumata, pakub samuti keelekeskkonda. Paraku õpilaste vastustest eestikeelse meedia tarbimine ei nähtu.

Samas ei pruugi keelekeskkonna puudumine väljaspool kooli tingimata välistada riigikeele head oskust. Edukamate koolide hulka kuulub näiteks Ida-Virumaa kool, kus 9. klasside õpilastel puuduvad kooliväliselt peaaegu igasugused eestikeelsed kontaktid. Selle kooli õpilaste vastustest nähtub, et eesti keele peaaegu ainus kasutusruum on küll kool, kuid peale eesti keele tundide ka ainetunnid (nt inimeseõpetus), kus aine mõistestik esitatakse paralleelselt eesti ja vene keeles. Samuti pakub mitmekesine projektitegevus õpilastele lisavõimalusi riigikeele suhtlusruumi laiendamiseks ja õpimotivatsiooni tekkeks: Mul oli selline juhtum, et meil koolis olid külalised Tartust ja üks poiss elas minu juures. Kui ma sain aru, et ma ei räägi hästi eesti keelt, sïs kohe tekkis motivatsioon keelt õppida.

Riigieksami tulemuste põhjal vähem edukate koolide õpilastel puuduvad intervjuudes öeldule tuginedes võimalused eesti keele kasutamiseks väljaspool koolitundi.

(3) Räägime ainult eesti keele tunnis, saame rääkida erinevatel teemadel, mitte ainult sellest, mida oli vaja õppida.

(4) Eesti keeles räägime ainult õpetajaga koolis. Kellega meil siis veel rääkida? Rohkem polegi kellegagi rääkida. Võib-olla ainult poes mõnikord läheb vaja.

(5) Eesti keeles räägime ainult koolis. Mul on kaks eestlasest sõpra, nendega üritan eesti keeles rääkida.

(6) Eestlastest sõpradega räägime ka inglise keeles, sest seda keelt oskame nii mina kui tema paremini kui mina eesti keelt või tema vene keelt.

\section{2. Õpilaste enesehinnang eesti keele oskuse kohta}

Teine põhiküsimus hõlmas 9. klasside õpilaste hinnangut enda eesti keele oskuse kohta. Küsimuse eesmärk oli uurida, millisel tasemel olevana näevad õpilased enda eesti keele oskust ning mil määral nad on suutelised eesti keeles suhtlema. Küsimus esitati vormis “Kuidas hindad enda eesti keele oskust?”. Rõhutame, et õpilastega vesteldi vene keeles ning nende eesti keele oskust eraldi ei testitud. Seega põhinevad vastused õpilaste subjektiivsetel hinnangutel. Peamiseks aruteluküsimuseks 
kujunes eesti keele valdamine osaoskuste kaupa (kõnelemine ja kirjutamine), millest omakorda kasvasid välja intensiivsed arutelud suhtlusoskuse arendamise tähtsusest ning kriitilised seisukohad eesti keele õppe liigse grammatikakesksuse kohta. On märkimisväärne, et õpilased hindavad eesti keele oskust üsnagi heaks, kõrge enesehinnang aga ei pruugi olla alati adekvaatne.

Edukamate koolide 9. klasside õpilased hindavad oma eesti keele oskuse väga heaks (Oleme oma eesti keele oskusega väga rahul). Rahulolu keeleoskusega selgitatakse tugevas koolis õppimisega, eesti keele õppe alustamisega 1. klassis, eestikeelse aineõppe ning nõudlike õpetajatega, aga ka õpilaste enda valmisolekuga eesti keele intensiivseks õppimiseks.

(7) Meie eksamitulemused on head, sest meil on väga nõudlikud õpetajad, nad nõuavad palju. Meie ise tahame kooli hästi lõpetada, sellepärast õpime palju.

(8) Oleme väga rahul, õpime eesti keelt esimesest klassist saadik, meil on ka teised ained eesti keeles.

(9) Kui me eestlastega suhtleme, siis nad imestavad, et me ei ole eestlased ja et meie eesti keel on nii hea. Oleme selle üle uhked.

Eesti keele oskuse head taset seostavad õpilased piisava praktikaga. Eeskätt Tartu õpilased näevad eestikeelses keelekeskkonnas teiste piirkondade noorte ees selget eelist riigikeele paremaks omandamiseks (Meil on kindlasti lihtsam ka tulevikus tööle saada kui teistel). Riigikeele eksami häid tulemusi seostatakse eesti keele "kohaloluga" kooliruumis ning eestikeelse aineõppega.

(10) Meil siin on head eksamitulemused, sest meil on koolis palju eesti keelt kuulda ja algkoolis ka õpitakse eesti keelt palju ja teised ained on ka eesti keeles.

Riigieksami tulemuste põhjal vähem edukate koolide õpilased hindavad samuti oma eesti keele oskuse heaks, kuid arutledes kriitiliselt keele osaoskuste teemadel, nimetavad ka nemad eesti keele õppes liigset grammatikakesksust, mis jätab tagaplaanile suulise eneseväljenduse arendamise. Õpilaste keeleoskust varjutab suhtlusvõimaluste ning toetava eestikeelse keskkonna puudumine. Kõik õpilased tõdesid riigikeele kasutusvõimaluste piiratust (Oskame küll, aga kus me seda ikka räägime) ning olid sellepärast ka oma suulise eneseväljendusoskuse suhtes pigem kriitilised.

(11) Keeleoskusega ei saa rahul olla ainuüksi selle pärast, et me küll õpime eesti keelt, aga me ei räägi seda kusagil ega saa ka harjutada.

(12) Ei ole rahul [eesti keele oskusega], sest kui trammis sõidan ja kuulen, kuidas eesti memmekesed räägivad, siis aru saan, aga vastu rääkida ei oska, ainult naeratan. Kui midagi küsitakse, siis ainult naeratan.

Intervjuudest võib järeldada, et keelekeskkonna puudumise kõrval ei toeta vähem edukate koolide õpilaste eesti keele õpet ka nende kodune keeleolukord, kus vanematel puudub laste kooliõpingutes aitamiseks piisav eesti keele oskus (Kodus keegi ei aita; Mul isa aitab mõnikord; Mõnikord aidatakse, aga vähe). Intervjuudes osalenud nelja kooli õpilastest vaid üksikute õpilaste kodus ja sugulasvõrgustikus suheldakse mingilgi määral eesti keeles (nt ühega vanematest või vanavanematega). 


\subsection{Riigikeele õppimise olulisus õppija vaatenurgast}

Õpilaste hoiakute väljaselgitamiseks esitati põhiküsimus sõnastuses "Miks on vaja eesti keelt õppida?", "Milleks läheb Sinu arvates vene noorel eesti keele oskust vaja?”. Arutelude käigus kasvas esitatud põhiküsimusest välja mitu alateemat, nt eesti keele "väiksus" ja keele tulevik, väljaränne, vene identiteet Eestis ja selle säilitamine, Ida-Virumaa koolides ka eestlaste ja venelaste suhted.

Riigikeele eksami tulemuste põhjal edukamate ja vähem edukate koolide 9. klasside õpilaste argumendid eesti keele õppimise vajalikkuse ning kasulikkuse teemadel ei erine üksteisest. On märkimisväärne, kuivõrd selgelt pragmaatiline on õpilaste suhtumine riigikeele oskuse vajalikkusesse ja kuidas õppimise kannustajaks on peaaegu eranditult kõigis vastustes instrumentaalne motivatsioon. Siinjuures tuleks juhtida tähelepanu, et ka artikli sissejuhatuses viidatud uuringus osalenud õpetajad ja koolijuhid ei pööranud tähelepanu integratiivsele motivatsioonile riigikeele õppes (vt Klaas-Lang jt 2014).

Edukamate koolide õpilaste vastused demonstreerivad riigikeele õppimise kohustust (See on ju riigikeel, me peame seda oskama), eesti keele õppimise vajalikkust seostatakse ka lähituleviku plaanide ning gümnaasiumisse astumisega (kuigi mitte kõik potentsiaalsed gümnasistid ei plaani haridusteed jätkata Eestis). Eesti keele õppimises nähakse kõige selgemat "kasu" selles, et edukas koolilõpetamine ning võimalikult heal tasemel eesti keele oskamine avab uksed õpingute jätkamiseks gümnaasiumiastmes või ülikoolis.

(13) Et eksam ära teha ja edasi õppida.

(14) Et gümnaasiumis või kutsekoolis õppida.

(15) Et saada gümnaasiumis hakkama.

(16) Et pärast ülikoolis saaks õppida.

(17) Et suhelda selles keeles ja/või õppida edaspidi samas keeles.

Ka vähem edukate koolide õpilaste argumentatsioonist nähtub selge pragmaatilisus, kus riigikeele õpe on üks kohustuslikest ainetest teiste seas, milles eksami sooritamine on vajalik põhikooli lõpetamiseks ning õpingute jätkamiseks gümnaasiumis. Eesti keele õppimisel on esiplaanil eeskätt instrumentaalne motivatsioon, kus riigikeele õppimist nähakse kohustusliku ning põhikooli lõpetamiseks vajaliku õppeaine või keelena.

(18) Teha eesti keele eksam ära, et saaks kooli lõpetada, ja kuna meil valikut pole, me peame selle eksami tegema.

(19) Et eksam ära teha ja edasi õppida.

(20) Et gümnaasiumis hakkama saada.

(21) Et paremasse gümnaasiumisse sisse saada.

Vaid vähesed õpilased seostavad eesti keele vajalikkust elamisega Eesti riigis. Eesti keel on Eesti territooriumil kõneldav põhikeel, mistõttu on vaja laiema üldsusega või avalikus ruumis suhelda eesti keeles: Kui selles riigis elada, sïs peaks keelt oskama; Eesti keelt on vaja selleks, et suhelda mü̈̈jatega. Oluliseks motivaatoriks riigikeele õppimisel peetakse ka Eesti kodakondsuse saamist: Tahan saada Eesti kodakondsust ja sellepärast õpin eesti keelt. Ka eelnenud vastused demonstreerivad siiski pigem vajadust ja kohustust, mitte aga tahtmist ja võimalust enesearenguks. 
Siiski tõid üksikud õpilased välja eri kultuuridega suhtlemise aspekti, mida võiks mööndustega seostada integratiivse motivaatoriga: Erinevates keeltes rääkides saab huvitavate inimestega suhelda.

Eesti keele valdamist peetakse oluliseks ka tööturul parema positsiooni saavutamiseks (Keel on tähtis, et tööd saada; Et saada paremat töökohta. Keelest sõltub palju, tutvused on ka tähtsad), kuid seda varjutab 9. klasside õpilaste selge kahtlemine vene emakeelega isikute konkurentsivõimes tööle kandideerimisel. Selgelt on kinnistunud tõekspidamine, et vene keele kõnelejatele seatakse Eesti tööturule pääsemiseks piiranguid. Tüüpkommentaarina kõigist intervjuudest kõlama jäänud arvamus Kui on valida eestlasest või venelasest töötaja vahel, sïs valitakse eestlane, hoolimata keeleoskusest markeerib selgelt 9. klasside õpilaste ettekujutust Eesti tööturu toimimisest. Eesti keele vajalikkust seostatakse ka isikliku majandusliku kasuga ning selle saavutamiseks peetakse oluliseks alustada õpinguid kohe eestikeelses koolis.

(22) Et pärast saaks parema töökoha, aga seal on ka tutvused tähtsamad. Meid sinna tööle nagunii ei võeta, venelasi ei võeta heameelega tööle. Isegi kui sa eesti keelt hästi oskad ja sul on kõrge kategooria, sind ei võeta tööle, kui on valida sinu ja eestlase vahel.

(23) Olen kindel, et mind ei valita, sest mul on vene perekonnanimi. See on kindlasti takistuseks. Mul tahtsid vanemad perekonnanime vahetada, aga ma ei taha. Kindlasti võetakse panka tööle see inimene, kelle perekonnanimi on Sibul, mitte Petrova. Minu peres on selline kogemus.

Samas nähtub argumentatsioonist ka inglise keele olulisus, mida peetakse (tasuva) töökoha saamisel eesti keele valdamise kõrval paralleelselt oluliseks.

(24) Hea töökoha saab, kui oskad eesti ja inglise keelt, muidu seda keelt pole vaja, kui ära lähed. Praegu kõik lähevad ära - eestlased ja venelased, sest tööd ei ole. Need, kes tahavad siin elada ja keelt hästi osata, peaksid kohe eesti kooli minema, siis on palju lihtsam.

Õpilaste argumentatsioonis tõuseb esile ka eesti keele väiksuse diskursus ning sellega seoses eesti keele väljasuremise või kadumise oht. Hoolimata eesti keele väga heast valdamisest, seadsid ka edukamate koolide õpilased eesti keele õppimise olulisuse keele väiksuse tõttu kahtluse alla. Samas kasutatakse intervjuudes adjektiivi väike üldsõnaliselt, toomata välja konkreetseid mõjureid, mis eesti keele kestlikkuse ohtu seaksid. Eesti keele kadumist nähakse selle "väiksuse" tõttu kui paratamatut protsessi, mis nagunii juhtub ning millega seatakse kahtluse alla keele õppimise otstarbekus (Milleks õppida midagi, mis nagunii ära kaob?). Niisugused seisukohad olid pigem üldised, sõltumata üldhariduskooli asukohast ja riigikeele eksamil saavutatud tasemest. Õpilaste argumentatsioonis peegeldub keeleõppe instrumentaalne funktsioon: kui keeles ei nähta otsest kasu, ei peeta selle õppimist vajalikuks.

(25) Eesti keelt pole vaja, see on nii väike keel, et see keel kaob varsti ära. Pole erilist mõtet seda keelt õppida.

Eesti keeles nähakse ka vene identiteedi ohustajat. Palju arutelu tekitas põhiküsimusest välja kasvanud küsimus, kas vene noor peaks õppima eesti- või venekeelses 
üldhariduskoolis. Kooli valikus nähakse seost rahvusliku identiteedi ning sellest võimaliku loobumise vahel. Eesti koolis õppimises nähakse ohtu enda vene identiteedi säilimisele ning eestikeelse kooli valikut peetakse võimalikuks vaid siis, kui tahad eestlaseks hakata. Õpilased on ka arvamusel, et

(26) Selline vene kool, kus eesti keelt on palju, on parem kui eesti kool. Laps peaks jääma ikka vene kultuuriruumi, sest mentaliteet on teine.

Sellelaadsed õpilasi vägagi erutavad arutelud toovad esile veel ühe dimensiooni, nimelt küsimuse vene noorte keelelisest ja rahvuslikust kuuluvusest ning mitmekeelsusest laiemas mõttes. Tõstatub ka küsimus, kas vene noore keelelise mitmekeelsuse üheks komponendiks võiks olla eesti keel. Intervjuud osutavad, et eesti keele õppimist või kõnelemist ei osata näha õpilase mitmekeelset ning -kultuurilist identiteeti kujundava komponendina. Enamiku intervjuudes osalenute jaoks pole eesti keelel vene ja inglise keele kõrval muud rolli kui üks kohustuslik õppeaine teiste seas. Õpilaste argumentatsioonist võib aimata, et võimalikuks peetakse vaid ükskeelsust ning ühekultuurilisust, mis välistab kuulumise kahte kultuuri. Eestlaseks hakkamine seostub vene emakeelega noore jaoks identiteedi ja rahvuse vahetamise, mitte aga kodanikuks olemisega. Võimalus, et eestlane võib tähistada ka vene emakeelega isikut, kes samastab ennast nii vene kui ka eesti kultuuriga, on mudel, mille peale vene koolinoor pole ilmselt mõelnud. Vene emakeelega noore kakskeelsus kui identiteedi komponent ja mitmekultuurilisus kui väärtus on leidnud küll tee koolide visioonidokumentidesse ja arengukavadesse, kuid tegelikus elus seda ei tunnetata (vt Klaas-Lang jt 2014). Vähemalt intervjuudes ei pööranud ükski vastanute grupp (õpilased, õpetajad, koolijuhid) taolistele eesmärkidele peaaegu mingit tähelepanu.

Olulise erinevusena eespool analüüsitud edukate koolide rühmast tõusevad vähem edukate koolide õpilaste vastustes kohati esile arvamused, kus eesti keele oskamist seostatakse õigusega elada Eestis. Eesti keele õppimises nähakse kohustusi Eesti riigi ees ning riigikeele oskuses Eestisse jäämise alust: See keel on sïn ja kui sa selles keeles aru ei saa, siis kuidas sa sïn elad? Riigikeele mitteoskamine võib õpilaste arvates kaasa tuua lausa drastilisi tagajärgi.

(27) [Keelt on vaja õppida ja osata selleks,] et meid ei pekstaks Eestist välja.

Eesti keele oskust peetakse aga tööturukeelena igati oluliseks. Ühtlasi ei pea vene emakeelega teismelised riigisektoris töötamist venekeelse inimese jaoks üldse võimalikuks.

(28) Eestis ilma eesti keeleta eriti hakkama ei saa, kui tahad enamat kui Sillamäel kükitada.

(29) Selleks et pärast hästi elada - hästi teenida, saada head tööd, kui sa siin Eestis elada tahad.

(30) Kui keelt ei oska, siis saad miinimumpalka.

(31) Eesti keele oskusest sõltub ka tulevane töökoht, aga see on vähem tähtis kui head tutvused. Siis kui sul on häid tuttavaid, siis saab ka hea töökoha äris. Riigiasutuses küll keegi töötada ei taha, ja meid sinna ei võeta ka.

Samas on ka Ida-Virumaa 9. klasside õpilased veendunud selles, et vene emakeelega inimestel on Eesti tööturule ilma tutvusteta võimatu siseneda, eriti riigisektorisse. 
Õpilaste argumentatsioonist nähtuvad ka selged ettekujutused era- ja riigisektori toimimise erinevustest, mida seostatakse samuti riigikeele oskusega.

(32) Kui on tutvused, siis saab igale poole tööle minna, siis pole ka keeleoskus tähtis. Erasektorisse saab igale poole tööle minna, kui tutvused on. Riigiasutustes kontrollitakse kõike.

Eesti keele õppimise vajalikkust või mittevajalikkust seostatakse ka võimaliku väljarändega. Eesti keele õppimine pole oluline, kuna välismaal ei lähe seda nagunii vaja.

(33) Paljud tahavad Eestist ära minna, Euroopasse või Venemaale, siis ikka inglise keelt läheb rohkem vaja. Seal eesti keelt ei lähe nagunii vaja.

\subsection{Eesti versus inglise keel}

Empiiriline ainestik kõneleb selgelt inglise keele kõrgemast prestiižist ning olulisemast rollist koolinoore argielus. Vene koolinoorte keelevalikud markeerivad laiemalt kahe rühma - eesti- ja venekeelse - suhtlusmallide muutumist, kus kahe rühma suhtlust võib vahendada hoopiski inglise keel. Pole ilmselt vale väita, et vene keele kõrval on noortel inglise keelega tihedamad kokkupuuted; võimalik, et seda osatakse suhtluskeele tasandil ka paremini kui eesti keelt ning inglise keelega ollakse ainuüksi popkultuuri ning sotsiaalmeedia mõju tõttu vahetumas kontaktis kui eesti keelega. Intervjuudes antud vastustest aimdub vene noorte valmisolek suhelda eesti eakaaslastega inglise keeles ning oletatavasti on see valmisolek vastastikune. Seega ei pruugi inglise keele eelistamine johtuda vaid vene noorte soovist, vaid ka eesti koolinoorte silmis võib inglise keelel olla suurem väärtus (noorte keelehoiakutest lähemalt Ehala, Tammemägi 2012), mistõttu ühiseks suhtluskeeleks valitakse "suurem" keel.

(34) Alati on nii, et kui kohtuvad eesti ja vene rahvusest noored, siis nad räägivad omavahel inglise keeles. Üritan öelda midagi eesti keeles, aga eestlane näeb, et ma pole eestlane ja kohe läheb inglise keelele üle.

(35) Inglise keel on lihtsam, seda läheb ka rohkem vaja, oleme ju Euroopas. Kui oleks selline olukord, et ümberringi ongi ainult eesti või mingi muu keel, siis ikka õpid ära, käidki sõnaraamatuga ringi ja õpid.

Paljud õpilased vahendavad intervjuudes vanemate arvamusi eesti keele kui mitteolulise keele kohta ning inglise keele kõrgemale positsioonile asetamise kohta. Intervjuudes öeldut tõlgendades nähtub, et õpilaste vanemad näevad sageli eesti keelt eeskätt vahendina millegi saavutamiseks (nt põhikooli lõpetamine, hea riigikeele oskuse abil paremasse gümnaasiumisse pääsemine jne).

(36) Vanemad ütlevad, et inglise keel on tähtsam.

(37) Ema ütleb, et pean kooli lõpetama ja selleks on eksam vaja teha.

(38) Minu peres ei räägi keegi eesti keelt, ema ütleb, et õpi eesti keelt, siis saad hea eksamihinde ja saad kooli lõpetada ja siit ära sõita.

Eesti keele olulisuse ning vajalikkuse temaatikast kasvas õpilastega tehtud intervjuudest kohati välja õpilaste hoiakuid detailsemalt avav alateema, nimelt küsimus, 
kas vene keelt emakeelena kõnelev õpilane ise paneks oma lapse eestikeelsesse kooli. Õpilaste antud vastused on eitavad ning esitatud väidete ning põhjendustega välistatakse järeltuleva põlvkonna õppimine eestikeelses koolis. Eesti keeles nähakse konkurenti vene keelele, mis seab ohtu nii vene keele kui ka vene identiteedi säilitamise laiemas mõttes. Eri keelte rollidest oma argielus kõneldes nähtub, et vene kooliõpilasele on ilmselt võõras mõelda endast kui mitme keele kõnelejast ning eesti keele kasutamises nähakse pigem liikumist identiteedi kaotamise, mitte aga enda (mitmekeelse ja -kultuurilise) identiteedi tugevdamise suunas. Artikli autorid peavad siinkohal vajalikuks rõhutada, et mitmekeelsuse tähenduse, selle defineerimise ning mõistmise teemadel intervjuudes pikemalt ei peatutud ning seega jääb praegu vastuseta küsimus, miks vene koolinoored just niimoodi mõtlevad. Võib arvata, et see johtub paljudest eri teguritest, mida on põhjust eraldi uurida.

(39) Õppisin neli aastat eesti koolis, aga tulin vene kooli üle, sest olen vene inimene ja tahan vene keeles õppida, suhelda. See oli minu, mitte minu vanemate valik.

(40) Ei paneks enda last eesti kooli, sest siis ta hakkab ainult eestlastega, mitte venelastega suhtlema.

(41) Eesti kooli keegi lapsi ei paneks, sest eesti keelt saab koolis õppida, aga emakeelt peab ikka oskama. Kui laps panna juba eesti lasteaeda, siis laps õpib eesti keele paremini selgeks kui oma emakeele [vene keele].

Õpilastega nende tulevikuplaanidest kõneldes nähtub, et enamik intervjuudes osalenuist ei seosta enda tulevikku Eestiga ning plaanib riigist lahkuda. Kuigi enamik kavatseb õpinguid siiski gümnaasiumis jätkata, soovitakse pikemas perspektiivis Eestist lahkuda. Vene keeles hariduse omandanute väga suur soov jätkuõpinguteks Eestist lahkuda on selgunud ka näiteks Praxise 2012. a uuringust "Koolilõpetajad ja nende karjäärivalikud” (Mägi, Nestor 2012), mille kohaselt vähemalt 30\% vene emakeelega gümnaasiumilõpetajatest soovib edasi õppida välismaal.

\section{Kokkuvõte}

Vene õppekeelega koolide 9. klasside õpilaste eesti keele kasutusväljad on suhteliselt ahtad ja seda just Ida-Virumaal, piirdudes valdava osa intervjuudes osalenutel koolikeskkonna ja/või eesti keele teise keelena tundidega. Kui väljaspool Ida-Virumaad (st Tallinnas ja Tartus) elavad õpilased kasutavad eesti keelt iga päev ka väljaspool kooli (nt huviringides, trennides, kaubanduses) ning isiklikes suhtlusvõrgustikes, siis Ida-Virumaa koolide õpilastel on piirkonna keelelisest-rahvuslikust eripärast tingituna eestikeelseks suhtluseks ootuspäraselt vähem võimalusi. Kui üldiselt hindavad noored oma riigikeele oskust heaks ja väga heaks (iseküsimus on sellise enesehinnangu adekvaatsus), siis üsnagi kriitilised ollakse oma eestikeelse suhtluspädevuse osas. Põhjusena tuuakse enamasti välja just väga vähene võimalus kooliväliselt eesti keelt kasutada.

Vene noore jaoks on eesti keel eeskätt kohustuslik õppeaine, keel, mille õppimise ja oskamise kohustus tuleneb eesti keele riigikeele positsioonist. Eesti keelt nähakse kui vahendit, et gümnaasiumis või kutsekoolis edasi õppida. Väga vähe (kui üldse) ilmneb eesti keele õppimises selle integratiivne motivatsioon ehk keeleõppija 
isiklikum suhe õpitavasse keelde ja kultuuri, eesti keele tunnetamine identiteedi osana. Kuigi koolide visioonidokumendid väärtustavad õpilaste kasvatamist mitmekeelseks ja -kultuuriliseks, ei pea õpilased selle väljatoomist oluliseks.

Intervjuudes esitatud argumentidest nähtub ilmne pragmaatilisus keeleõppes ja -valikutes ning oluliseks keeleks peetakse keelt, mis on "suurem" ning "tuntum" ning mis võimaldab nende omaduste kaudu keelekasutajale laiemaid isiklikke hüvesid, nii praegu kui ka tulevikku vaatavalt. Eesti keel oma väiksuse ja "kadumisohuga" võib samuti pärssida õpimotivatsiooni. Õpilastega nende tulevikuplaanidest kõneldes nähtub, et enamik intervjuudes osalenuist ei seosta enda tulevikku Eestiga ning plaanib riigist lahkuda. See on ilmselt ka üks põhjustest, miks rõhutatakse inglise keele õppimise vajalikkust.

Ka eesti koolinoorte suhtumine keelde on kohati pragmaatiline, mis ilmnes Ehala ja Tammemäe (2012) uuringus, kus instrumentaalsest aspektist lähtuvalt väärtustasid õpilased enim inglise keele oskust. Küll aga väärtustasid eesti koolinoored eesti keelt just tunnetuslikust ja kultuurilisest ehk siis integratiivsest aspektist. On mõistetav, et sellist tunnetuslikku väärtust kannab venekeelse noore jaoks tema emakeel ehk siis vene keel. Intervjuude põhjal võib ka öelda, et vene-eesti kakskeelsus ja mitmekultuurilisus ei kuulu, vähemalt praegusel momendil, venekeelse noore tunnetuslike väärtuste paradigmasse. Uuringu tulemuste kontekstis on uudne just mitmekeelsuse- ja kultuurilisuse probleemistik, mis avardab oluliselt vene koolinoore riigikeele hoiakute tagamaid. Kas ja kuivõrd mitmekultuuriline identiteet võiks olla õpimotivatsiooni soodustavaks teguriks, väärib edasistes uuringutes detailsemat vaatluse alla võtmist.

\section{Viidatud kirjandus}

Dörnyei, Zoltán 1998. Motivation in second and foreign language teaching. - Language Teaching, 31 (3), 117-135. http://dx.doi.org/10.1017/S026144480001315X

Dörnyei, Zoltán 2001a. New themes and approaches in second language motivation research. - Annual Review of Applied Linguistics, 21 (1), 43-59. http://dx.doi. org/10.1017/So267190501000034

Dörnyei, Zoltán 2001b. Teaching and researching motivation. Applied Linguistics in Action Series. Essex: Pearson Education Limited.

Dörnyei, Zoltán 2003. Attitudes, orientations, and motivations in language learning: Advances in theory, research, and applications. - Language Learning, 53 (S1), 3-32. http:// dx.doi.org/10.1111/1467-9922.53222

Dörnyei, Zoltán; Schmidt, Richard (Eds.) 2001. Motivation and Second Language Acquisition. University of Hawai'i at Mānoa: Second Language Teaching \& Curriculum Center.

Ehala, Martin; Tammemägi, Anni 2012. Eesti õpilaste keelehoiakud 2011. aastal. [Language attitudes of secondary school students 2011.] - Keel ja Kirjandus, 4, 241-260.

EKR 2007 = Euroopa keeleõppe raamdokument: õppimine, õpetamine, hindamine. [Common European Framework of Reference for Languages: Learning, Teaching, Assessment (CEFR).] Tartu: Haridus- ja Teadusministeerium.

Ellis, Rod 2008. The Study of Second Language Acquisition. Oxford: Oxford University Press.

Ellis, Rod; Barkhuizen, Rod 2005. Analysing Learner Language. Oxford: Oxford University Press.

Gardner, Robert C. 1985. Social Psychology and Second Language Learning: The Role of Attitudes and Motivation. London: Arnold.

Gardner, Robert C. 2010. Motivation and Second Language Acquisition: The Socio-Educational Model. New York: Peter Lang. 
Garrett, Peter 2010. Attitudes to Languages. Key Topics in Sociolingustics. Cambridge: Cambridge University Press.

Jalkanen, Liisa; Ruuska, Johanna 2007. Affektiiviset tekijät vieraan kielen opiskelussa. Tapaustutkimus alakoulun englannin tunnista oppilaiden kokemana. [The Affective Factors in Studying a Foreign Language: A Case Study of the English Lessons in the Primary School as Experienced by the Pupils.] Pro gradu -tutkielma. Jyväskylä: Jyväskylän yliopisto.

Kaksi kantaa pakkoruotsista. [Two opinions on mandatory Swedish in Finland.] http://www. hs.fi/sunnuntai/a1305708043006 (12.10.2014).

Klaas, Birute 1992. Mõtteid võõrkeeleõpetuse psühholoogiast. [Some thoughts about the psychology in foreign language teaching.] - Lähivertailuja 5: Suomalais-virolainen kontrastiivinen seminaari Viroilla 27. ja 28. syyskuuta. Maia Väkram (Toim.). Tampereen yliopiston suomen ja yleisen kielitieteen laitoksen julkaisuja 15. Tampere: Tampere University Press, 29-33.

Klaas-Lang, Birute; Praakli, Kristiina; Peedisson, Anni; Lašmanova, Alla 2014. Arvamusi ja hinnanguid riigikeele õppe korraldamise kohta vene õppekeelega koolides. Uuringu lõpparuanne. [Opinions and Assessments on Teaching of Estonian in Russian-Medium School. Final Report.] Tartu: Tartu ülikooli eesti ja üldkeeleteaduse instituut.

Knight, Tiina 2013. Pelkkää pakkoruotsia? Tamperelaisten yliopisto-opiskelijoiden ruotsin kielen opiskelimotivaatio. [Mandatory Swedish Only? Students Motivation to Study Swedish at the University of Tampere.] Pro gradu -tutkielma. Tampere: Tampereen yliopisto.

Koreinik, Kadri 2011. Language Ideologies in the Contemporary Estonian Public Discourse: With a Focus on South Estonian. Dissertationes sociologicae universitatis Tartuensis 5. Tartu: Tartu University Press.

Koreinik, Kadri; Praakli, Kristiina 2013. Keele kestlikkuse ja kao konstrueerimine poolavalikes diskursustes. [The construction of language maintenance and loss in semi-public discourses.] - Eesti Rakenduslingvistika Ühingu aastaraamat, 9, 131-148. http:// dx.doi.org/10.5128/ERYag.09

Metslang, Helena; Kibar, Triin; Kitsnik, Mare; Koržel, Jevgenia; Krall, Ingrid; Zabrodskaja, Anastassia 2013. Kakskeelne õpe vene õppekeelega koolis. [Bilingual Learning in Russian-Medium Schools. Final Report.] Tallinn: Tallinna Ülikooli eesti keele ja kultuuri instituut.

Mitchell, Rosamond; Myles, Florence 2004. Second Language Learning Theories. Second edition. London-New York: Routledge.

Mägi, Eve; Nestor, Mihkel 2012. Koolilõpetajad ja nende karjäärivalikud. Keskharidusastme lõpetajate valikute uuringu lõpparuanne. [Survey of Upper-Secondary Graduates' Educational Choices.] SA Poliitikauuringute Keskus Praxis. http://praxis.ee/fileadmin/ tarmo/Publikatsioonid/Koolilopetajad uuring.pdf (12.10.2014).

Pihko, Marja-Kaisa 2007. Minä, koulu ja englanti. Vertaileva tutkimus englanninkielisen sisällönopetuksen ja perinteisen englannin opetuksen affektiivista tuloksista. [Me, School and English: A Comparison of Affective L2 Learning Outcomes in CLIL Classrooms and EFL Classrooms.] Opettajankoulutus-laitoksen tutkimuksia 85. Jyväskylä: Jyväskylän yliopisto.

Proos, Ivi 2005. Eestivenelaste keeleoskus ja suhtumine 2007. aasta gümnaasiumireformi. Uuringu "Integratsiooni monitooring 2005" aruanne. [Language Skills of Estonian Russians and the Attitude Toward the Educational Reform in 2007.] Tallinn: Tallinna Ülikooli rahvusvaheliste ja sotsiaaluuringute instituut.

Proos, Ivi; Pettai, Iris 2008. Eestivene noored: uue põlvkonna positsioon ja ootused. [Estonian Russian Youths: The Position and Expectations of the New Generation.] Tallinn: Eesti Avatud Ühiskonna Instituut. http://uuringud.tallinnlv.ee/document.aspx?id=11178 (17.2.2015). 
TNS Emor 2006 = Eestikeelne aineõpe vene õppekeelega koolides: hetkeolukord ja vajadused. [Content and Language Integrated Learning (CLIL) in Russian-Medium Schools: Current Situation and Needs.] https://dspace.utlib.ee/dspace/handle/10062/40647 (2.1.2015).

TNS Emor 2008 = Mitte-eestlaste teadlikkus ja suhtumine vene õppekeelega koolide gümnaasiumiastmes eestikeelsele aineõppele üleminekust. [Non-Estonians' Awareness of and Attitude towards the Transition of Russian-Medium Schools to Teaching Subjects in Estonian at the Upper Secondary School Level.] https://dspace.utlib.ee/dspace/ handle/10062/40654 (2.1.2015).

Vaiss, Natalia 2009. Vene õppekeelega põhikooli õpilaste ja õpetajate hoiakud eestikeelse aineõppe suhtes vahetult enne 2007. aasta gümnaasiumireformi algust. [Attitudes of Russian-medium school learners and their teachers towards partial Estonian language instruction before implementation of the education reform in 2007.] - Eesti Rakenduslingvistika Ühingu aastaraamat, 5, 287-301. http://dx.doi.org/10.5128/ERYa5.19

Vare, Silvi 2004. Eesti keel vene koolis. [Estonian Language in Russian-Medium School.] Tallinn: Eesti Keele Sihtasutus.

Birute Klaas-Lang (Tartu Ülikool) on erialalt eesti filoloog, kelle peamised uurimisteemad on keeletüpoloogia, keelekontaktid, keelepoliitika, väliseesti keel.

Tartu Ülikool, eesti ja üldkeeleteaduse instituut, Jakobi 2, 51014 Tartu, Estonia

birute.klaas-lang@ut.ee

Kristiina Praakli (Tartu Ülikool) on erialalt eesti filoloog, kelle peamised uurimisteemad on väliseesti keel, keele kestlikkus ja keelekontaktid.

Tartu Ülikool, eesti ja üldkeeleteaduse instituut, Jakobi 2, 51014 Tartu, Estonia

kristiina.praakli@ut.ee 


\section{WHY DO I NEED ESTONIAN? \\ THE IMPORTANCE OF OFFICIAL LANGUAGE \\ COMPETENCE IN THE EYES OF RUSSIAN TEENAGERS}

\section{Birute Klaas-Lang, Kristiina Praakli \\ University of Tartu}

The aim of the article is to analyze the attitudes of 9th grade students at Russianmedium general education schools in Estonia toward the importance of competence in the official language. Semi-structured group interviews allow the voice of the language learner - in this case 15-16-year-old Russian school students - to be heard in the discussion of official language instruction. The analysis of these interviews reveals that Russian students' attitudes toward the official language are shaped by their perception of Estonian as a small language, limited opportunities to use the language in their immediate environment, and the role of different languages on the job market, but also by the students' national and linguistic identity. One primary conclusion is that in these students' eyes, the Estonian language has only instrumental value, that is, it is seen merely as a tool needed for self-actualization. Russian youths do not see the Estonian language as part of their identity, and question its sustainability (and therefore the benefit of studying it) in comparison to larger world languages.

Keywords: motivation, attitude, Russian-medium school, Estonian 